\title{
Analysis of Fouling in Sewage Source Heat Pump Heat Exchanger
}

\author{
Xu Zhang ${ }^{1, a^{*}}$, Lingzhe Zhang ${ }^{2, b}$ \\ ${ }^{1}$ Hebei university of science and technology, Shijiazhuang, Hebei Prov, China \\ ${ }^{2}$ Beijing Jiaotong University Haibin College,Huanghua City,Hebei Prov,China \\ ahongzi1208@126.com, b 694625292@qq.com
}

Keywords: sewage source heat pump; dirtiness resistance; bellows; anti-fouling characteristics Abstract. The characteristics of sewage source heat pump and the fouling problem are analyzed in article; four kinds of fouling resistance models, the fouling categories, influencing factors of fouling formation in the heat exchangers, and two kinds of heat exchangers fouling elements were provided. The comparison of fouling properties in smooth and bellows tubular heat exchangers were proposed, which draws a conclusion that the bellows anti-fouling characteristics performed superior to the smooth pipe.

\section{Introduction}

Heat pump is a device which provides both heat and refrigeration. Technical conditions and economical characters of heat pump are closely related to the characteristics of heat source. In recent years, with the increase of energy consumption, people began to pay attention to waste re-use issues, which involved the urban sewage heat energy that have performed warm in winter and cool in summer, the water temperature varies within a small range affected by climate, assigns a large stock of heat energy. It is suitable as the heat source of the water source heat pump system and the pump into the sewage source heat pump.

The development of sewage source heat pump has great advantages related to other heat pumps, such as huge amount of urban sewage discharge, rich sewage source; better economic benefits; expanding new space for the application and development of renewable energy; becoming an effective way of municipal sewage reclamation ${ }^{[1]}$. Nevertheless due to the high impurity content in urban sewage, the fouling of heat exchanger is a problem to be solved in sewage source heat pump systems.

\section{Fouling Resistance Model}

Fouling, the solid or muddy material accumulated gradually on solid surface connected with the fluid, is usually as a form of mixture. Fouling is a very common existence. The communication survey about of 3000 types of heat exchangers in New Zealand 1100 enterprises showed that more than $90 \%$ heat exchangers had fouling problems at different degrees of fouling problem [2,3]. For sewage water source heat pump, the heat exchanger is more prone to fouling because of the particularity of the water quality. As the reason of a poor conductor behavior for heat, once the fouling appears on heat transfer surface, the thermal resistant to heat will be increased between fluid and heat transfer. Therefore the fouling resistance is defined as the additional thermal resistance following the formation of the fouling:

$$
R_{f}=\frac{1}{U_{f}}-\frac{1}{U_{c}}
$$

Above formula:

$\mathrm{R}_{\mathrm{f}}$-thermal resistance at fouling sedimentary deposit; units: $\mathrm{m}^{2} \cdot \mathrm{K} / \mathrm{W}$;

$\mathrm{U}_{\mathrm{f}}$-heat transfer coefficient of scaling heat transfer, units $\mathrm{W} /\left(\mathrm{m}^{2} \cdot \mathrm{K}\right)$;

$\mathrm{U}_{\mathrm{c}}$ - heat transfer coefficient of clean heat transfer, units $\mathrm{W} /\left(\mathrm{m}^{2} \cdot \mathrm{K}\right)$.

A large number of observations show that the time-varying of the fouling resistance as Figure 1, after the contacting of clean heat transfer surface and the fluid. Of which the Line 1 showed as linear growth, Curve 2 showed as drop rate, Curve 3 showed as power law rate, Curve 4 showed as progressive. But the actual 
measurement of the fouling as time-varying generally is not as smooth as the Curve 1-4, but as the zigzag type showed as Curve 5. Curve 5 shows the time-varying of the fouling resistance of the particles in the river water which as the cooling medium of a HTRI.

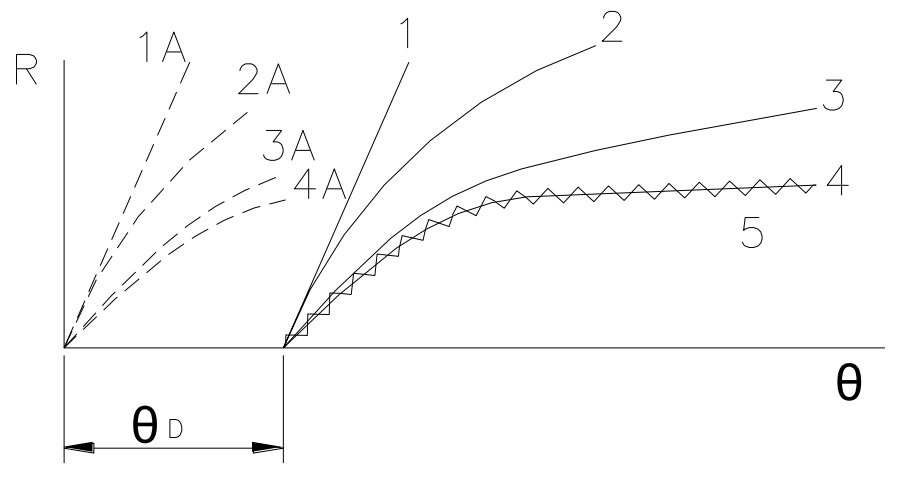

Fig.1. Time-varying fouling resistance

Linear fouling model:

$$
R_{f}(\theta)=B \theta \quad \theta \geq 0
$$

Power-law fouling model:

$$
R_{f}(\theta)=B \theta^{n} \quad \theta \geq 0
$$

Drop rate fouling model:

$$
R_{f}(\theta)=B \ln \theta \quad \theta \geq 1
$$

Progressive fouling model:

$$
R_{f}(\theta)=R_{f}\left(1-e^{-\theta / \theta_{c}}\right) \quad \theta \geq 0
$$

Above formula: $\mathrm{R}_{\mathrm{f}}$-thermal resistance at fouling sedimentary deposit; units $\mathrm{m}^{2} \cdot \mathrm{K} / \mathrm{W}$;

$\theta$ - time, units s.

\section{Classifications of Fouling}

According to the main physical and chemical process of the fouling formation, the fouling can be divided into seven categories as follows:

Crystallization Fouling: refers to the inorganic salt crystallization from oversaturated fluid solution which precipitated on the heat transfer surface, which is also called crystallization fouling. When the fluid refers to cooling water or liquid in evaporation equipment, the fouling is also called dirt scale or rust. In general, normal solubility salt is precipitated on the cooling surface, and abnormal solubility of insoluble or slightly soluble salt will be precipitated on the heating surface.

Particulate Fouling: refers to the accumulation of solid particulate suspended in a fluid in the heat exchanger surface. This fouling includes the gravity settling of the larger solid particles in the horizontal heat exchange surface, i.e., the sediment of the colloidal particles formed by the other mechanisms.

Chemical Reaction Fouling: refers to the sediment formed by the chemical reactions in the heat exchanger surface. But it does not include the involvement of the heat exchanger surface material itself. The polymerization and cracking of hydrocarbons, for example, are examples of these chemical reactions.

Corrosion Fouling: this fouling is caused by the accumulation of corrosion caused by the chemical reaction of the material itself. This kind of fouling not only pollute the heat transfer surface itself, but also may cause other potential fouling components attached to the heat exchange surface and form a fouling layer. 
Biofouling: this is made by bacteria, algae and other microorganisms and their discharge deposited on the solid surface and the formation of the growth and reproduction of biological mucosa (called bilfilm) or organic matter (called organic film).

Solidification Fouling: refers to the solidification of the working medium or their components curdled in the supercooled heat exchange surface.

Composite Fouling: above these six types of fouling, the formation mechanism of the same kind of fouling is basically the same. In a heat transfer process, the above six kinds of fouling mechanism in the formation of fouling caused by more than one mechanism, is called composite fouling[4]. In composite fouling formation processes, a phenomenon of mutually reinforcing occurs between several mechanisms frequently, known as synergistic effect of composite fouling synergy.

\section{Influence Factors of Fouling Formation of Sewage Source Heat Pump Heat Exchanger:}

After observation and research, the influence factors of fouling in heat exchanger are as follows:

Effect of fluid velocity on the surface of heat exchanger:

There are two parts in the influence of fluid velocity on fouling. First is the influence of the fouling sediment, and the second is the influence of the fouling erosion.

Most of the studies show that the growth rate of fouling ( $d m_{f} / d \theta$ ) decreases with the increase of the velocity of the fluid. Although the erosion rate $\left(\dot{m}_{r}\right)$ increases with the increase of the fluid velocity, it is more significant than the increase of the fouling rate of deposition $\left(\dot{m}_{d}\right)$, so the total growth rate $\left(d m_{f} / d \theta\right.$ ) decreases.

Temperature Affect

The temperature here includes the temperature of the heat exchange surface and the temperature of the fluid. The reason of effect of temperature on fouling is not very full well, and there is no unified opinion. There is a study shows that the temperature increasing can increase the amount of fouling, but there also exists different opinions.

Fluid temperature also has certain influence on fouling formation, and it is usually assumed as affecting polymerization rate, the rate of a chemical reaction and purification rate. So increasing the temperature of the fluid usually leads to increase of the fouling growth rate.

Effect of Structure Parameters of Heat Exchanger

Some parameters of the heat exchange surface, such as heat transfer surface material, state and the form, geometry size of the heat exchange surface, have obvious influence on the formation of fouling.

Observation indicates that the induction period of all kinds of fouling decrease with heat transfer surface roughness increases, because the concave portion of rough surface provides sediment the place to avoid flushing fluid, and it is conducive to deposition of fouling. Further, the surface roughness is also beneficial to the turbulent diffusion deposition and erosion progresses. A large number of experiments show that, increasing the heat transfer surface roughness can inhibit the fouling of heat exchanger[5].

Different structure and size of the heat exchanger has a different anti-fouling ability. In general, the higher the heat exchanger fluid velocity and greater turbulence intensity, the more difficult the fouling deposited, that is, the heat exchanger gets no picnic to scale.

Effect of Heat Exchanger Surface Fluid Properties

Here involved the effects of fluid nature to heat exchanger fouling include two aspects, one is the impact properties of the fluid itself, such as $\mathrm{pH}$ value, content of various salts (calcium, magnesium, and carbonate alkalinity) and concentration; in addition to the nature of the various substances which is insoluble or entrained in fluid, including insoluble object or entrained objects concentration, particle size and other factors. 


\section{Scaling Properties of the Smooth pipe and bellows}

On account of more impurities contained in wastewater containing, using plate heat exchanger leads to easier blocking., so the application of water source heat pump is not advocated as the use of plate heat exchangers, and shell pipe heat exchanger is recommended usually.

Experiments, compared of scaling properties between the smooth pipes and bellows, were set at the same flow rate, the substantially same fluid inlet temperature, and the same hardness of cycle fluid conditions. Curve obtained in experiments about fouling resistance $\mathrm{Rf}$ and time t were shown in Fig.2.

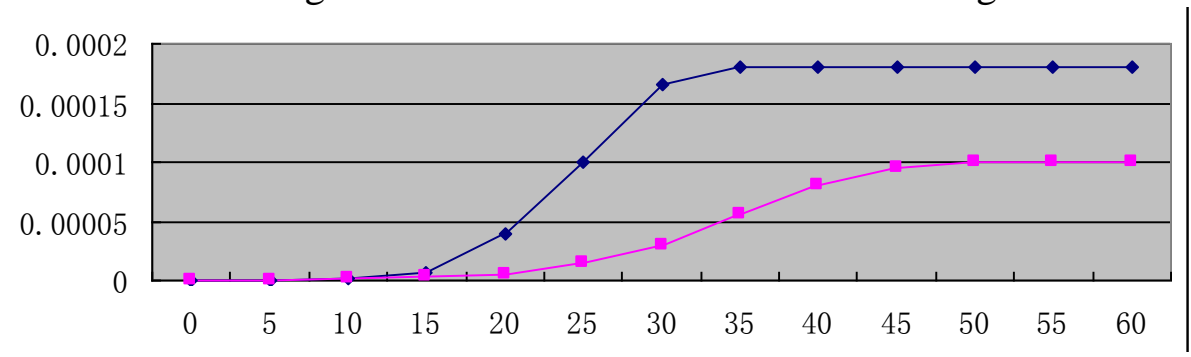

Fig.2. Scaling properties of the light tubes and bellows

As could be seen from Fig.2: at the beginning, the fouling resistance of the bellows and the smooth pipes were zero. Upon a time, fouling resistance had a sharp increase with time increase in time, and eventually reached a value substantially constant. Experimental results showed that the progressive value of fouling resistance of smooth pipe was larger than bellows, but the bellows' fouling induction period reached a constant asymptotic value, which take as 45 hours, was longer than smooth pipe, which take as 35 hours. It suggested that the bellows had a significant anti-fouling properties following with a strong heat transfer performance. The main reason was that the flow field inside the bellows alternately changed, not only to strengthen the internal pipe flow field disturbance, enhance heat transfer performance, but also enhance the rate of fouling denudation. Due to the scouring action of the fluid increases near the wall of bellows, a result of a increasing rate of fouling denudation, declining of fouling rate, making anti-fouling performance enhance consequently.

\section{Heat Exchanger Cleaning___Descaling}

Even with a good design, efficient operation and maintenance, the heat exchanger will generate fouling in the running for a while. The presence of fouling results to a decrease of heat transfer efficiency of the heat exchanger, a increase of the flow resistance, even failure or blockage. Therefore the heat exchanger must be cleaned regularly to remove fouling on heat transfer surface, to restore the performance of the heat exchanger.

In general, there are two methods to clean fouling on the heat exchange surface: mechanical cleaning and chemical cleaning.

\section{Mechanical Cleaning}

Mechanical cleaning is making fouling peeled off from the heat surface caused by forces, conducted by flow or mechanical, acoustic, thermal, optical and other effects of the fluid, and the forces is larger than fouling adhesion forces. Mechanical cleaning also includes spray water cleaning, spray steam cleaning, sandblasting cleaning, dry ice cleaning, air blast cleaning etc. for fouling cleaning on different occasions.

The advantages of mechanical cleaning is: it can remove out the charring fouling and hard fouling which are cannot removed by chemicalcleaning methods, and the heat exchanger material loss is small. However, when using mechanical cleaning, usually the equipment must be disintegrated, which may relate to the longer time, and higher cost. Of course, the disintegration device is also favorable on the one hand, such as repairing or replacing damaged heating surface when cleaning.

Chemical Cleaning 
Chemical cleaning precisely is adding detergents in the fluid to reduce the adhesion between fouling and heat transfer surfaces, then making fouling peeled off from the heated surface.

Chemical cleaning has some advantages such as clean uniformly, avoid damage on the metal surface, preventing rust after cleaning (because of the rust prevention and passivation), do not have to take apart the device, complete on the spot, and has a lighter labor-intensive than mechanical cleaning, etc. But it is difficult to remove carbon fouling. if cleaned mishandled or inhibitors used improperly, it can cause the corrosion of equipments. Additionally, cleaning of waste will pollute the environment, which causes the waste cannot be discharged directly, and it must be addressed.

In practice, taking which kind of cleaning methods of the heat exchanger depends on the specific circumstances. Not only choose the right cleaning methods, but also consider the issues of cleaning cycle.

\section{Summary}

In the increasingly serious energy crisis today, development of new energy and efficiency of using energy have become an important task, and sewage is being recognized as a clean energy which is yet to be developed and utilized., which belongs to the category of renewable energy. So in big cities, the development and application of sewage source heat pump is an effective way to change the status quo of cities, whose energy consumption structure base on coal. At present, the research on the urban sewage source heat pump focuses on the two stage of the urban sewage treatment plant, and the engineering scale is large, the application technology is also relatively simple and mature. The application process and operation management of the untreated sewage is less, and the operation and management are complicated, further, the problem of congestion problem of fouling machines and the scaling formation problem of fouling heat exchanger are still need to be solved.

\section{References}

[1] Yaqin Hou, Sewage Source Heat Pump System and Its Application, J. Energy Saving and Environmental Protection. 2011 (01) 72-73

[2] Suitor J W, Marner W J, Ritter R B, The History and Status of Research in Fouling of Heat Exchanger in Cooling Water Service, J. The Canadian Journal of Chemical Engineering.1977 (55)374-380.

[3] Min Zhao, Qiangli Kang, et al. Cause Analysis of Fouling in Heat Exchanger and Its Anti-scaling

Measures, J. Corrosion \& Protection. 2009(10)751-752

[4] Nebot E, Casanueva J F, Casanueva T, et al. Model for Fouling Deposition on Power Plant Steam

Condensers Cooled with Seawater: Effect of Water Velocity and Thbe Material. Heat Mass Transfer. 2007(50) 3351-3358

[5] Wei Zhang, Guanqiu Li, et al. Fouling Analysis Model Based on Prandtl Analogy in Screwed Pipe, J. Proceeding of the CSEE. 2008 (35) 66-70 